\title{
A NEW METHOD FOR SYNTHESIS OF EPITAXIAL FILMS OF SILICON CARBIDE ON SAPPHIRE SUBSTRATES $\left(\alpha-\mathrm{Al}_{2} \mathrm{O}_{3}\right)$
}

\author{
S.A. Kukushkin ${ }^{1-3}$ A.V. Osipov ${ }^{1,2}$, A.V. Redkov ${ }^{1}$, A.S. Grashchenko', \\ N.A.Feoktistov ${ }^{1,4}$, S.D. Fedotov ${ }^{5,6}$, V.N. Statsenko ${ }^{5}$, E.M. Sokolov ${ }^{5}$ \\ and S.P. Timoshenkov ${ }^{6}$
}

${ }^{1}$ Institute of Problems of Mechanical Engineering, Russian Academy of Sciences, Bolshoi pr. 61, St. Petersburg, 199178, Russia

${ }^{2}$ National Research University of Information Technologies, Mechanics and Optics, pr. Kronverkskii 49, St. Petersburg, 197101, Russia

${ }^{3}$ Peter the Great Saint-Petersburg Polytechnic University, Politekhnicheskaya ul. 29, St. Petersburg, 195251, Russia

${ }^{4}$ A.F.loffe Physico-Technical institute of RAS, Politekhnicheskaya str. 26, St.Petersburg, 194021, Russia ${ }^{5}$ Epiel JSC, $1^{\text {st }}$ Zapadny proezd, bld. 2, Zelenograd, Moscow, 124460, Russia

${ }^{6}$ National Research University of Electronic Technology - MIET, Bld. 1, Shokin Square, Zelenograd, Moscow, 124498, Russia

Received: March 15, 2018

\begin{abstract}
A fundamentally new method for synthesis of thick (200-400 nm) epitaxial films of silicon carbide on single-crystal $\mathrm{Al}_{2} \mathrm{O}_{3}$ substrates is proposed. The method develops the previously discovered method of topochemical substitution of atoms during the transformation of $\mathrm{Si}$ into $\mathrm{SiC}$. In the proposed method, a layer of epitaxial Si of orientation (100) or (111) is being preliminarily deposited on the sapphire via CVD or other technique. Then, using a topochemical reaction between the $\mathrm{CO}$ gas and the deposited epitaxial silicon film, a part of $\mathrm{Si}$ atoms is being substituted by carbon atoms. As a result, the silicon film transforms into SiC film. As experimental studies have shown, in the process of this transformation a high-quality epitaxial SiC layer can be formed on the sapphire surface under certain synthesis conditions. A detailed investigation of grown $\mathrm{SiC}$ layers using the methods of electron diffraction, ellipsometry, Raman spectroscopy, X-ray diffractometry and scanning microscopy is conducted and an analysis of experimental data is given. Formation of both cubic $3 \mathrm{C}-\mathrm{SiC}$ and hexagonal $\mathrm{SiC}$ polytypes during the transformation of $\mathrm{Si}$ into $\mathrm{SiC}$ was revealed by the XRD method. A detailed analysis of the current state of the problems of growth of epitaxial $\mathrm{SiC}$ layers on $\mathrm{Al}_{2} \mathrm{O}_{3}$ using various methods is provided. The method developed in this study opens up completely new perspectives not only for synthesis of semiconductors, but also for creation of new classes of composite, heat-resistant and other solid coatings.
\end{abstract}

\section{INTRODUCTION}

\subsection{Basic physicochemical principles of growth of SiC-on-Si films by the method of atomic substitution}

In papers [1-4] a new method for growth of nano$\mathrm{SiC}$ epitaxial films on $\mathrm{Si}$ was theoretically predicted and experimentally proved. The method itself and the technology of growth of nano-SiC developed on its basis [3,4] are fundamentally different from all currently existing methods and technologies for growth of single crystals, films and nanostructures. This method is based on the "assembly" of a new silicon carbide matrix on the basis of the old silicon matrix by partial substitution of silicon atoms in the substrate by carbon atoms. "Assembly" of the $\mathrm{SiC}$ matrix is carried out by chemical reaction (1): 


$$
2 \mathrm{Si}(\text { cr })+\mathrm{CO}(\text { gas })=\mathrm{SiC}(\text { cr })+\mathrm{SiO}(\text { gas }) \uparrow .
$$

A series of studies conducted in [3-6] proved that reaction (1) proceeds through two intermediate stages. In the first stage of the reaction $\mathrm{CO}$ molecule interacts with the surface of the silicon substrate and decomposes into a carbon atom and an oxygen atom. The oxygen atom reacts chemically with a $\mathrm{Si}$ atom, as a result of which $\mathrm{SiO}$ gas is being formed. Then $\mathrm{SiO}$ gas leaves the system, and a vacancy is being formed at the site of the silicon atom, which became a part of $\mathrm{SiO}$ molecule. The active (energetically excited) carbon which appeared as a result of the chemical reaction from $\mathrm{CO}$ molecule shifts to an interstitial position in the silicon lattice. This stage can be written as follows.

$$
\begin{aligned}
& \mathrm{CO}(\text { gas })+\mathrm{Si}(\text { crystal })= \\
& \mathrm{C}(\text { point defect in } \mathrm{Si})+V_{\mathrm{si}}+\mathrm{SiO} \uparrow(\text { gas }),
\end{aligned}
$$

where $V_{\mathrm{Si}}$ is the silicon vacancy.

Namely at this stage the intermediate phase of so-called "pre-carbide" silicon is being formed. This phase represents silicon saturated with pairs of defects $\mathrm{C}+\mathrm{V}_{\mathrm{Si}}$.

As follows from (2), point dilatation defects $C$ and $V_{\mathrm{Si}}$ are being formed and disappear in pairs. Note that point defects (carbon and vacancy) must be strictly located along a certain crystallographic direction [111] in Si. Only in this case, due to elastic mechanical attraction of dilatation defects [7], their total elastic energy is zero. In other cases, and along other crystallographic directions in Si reaction (2) does not proceed. "Pre-carbide" silicon is actually silicon, where every second $\mathrm{Si}$ atom is replaced by $\mathrm{C}$ atom due to reaction (2). Thus, in such silicon a single cell contains 4 pairs of dilatation defects and in "pre-carbide" silicon everything is ready for the transformation into silicon carbide. This process occurs at the next stage of the reaction, which can be described by Eq. (3):

$$
\begin{aligned}
& \mathrm{Si}(\text { crystal })+\mathrm{C}(\text { point defect in } \mathrm{Si})+V_{\mathrm{si}}= \\
& \mathrm{SiC}(\text { crystal }) \text {. }
\end{aligned}
$$

At this stage, carbon atoms are being displaced in a consistent manner towards silicon vacancies, and silicon carbide appears. Resulting heterogeneous reaction (1) is obtained by summing up the stages (2) and (3). The elastic interaction between pairs of point dilatation defects $C$ and $V_{\mathrm{si}}$ determines the kinetics of reaction (1). It is important to emphasize that first-order phase transition (3) proceeds without breaking of bonds between atoms and form- ing new bonds. This in fact ensures a high crystalline perfection of the silicon carbide film. Such transformation is always accompanied by formation of voids, since the volume of $\mathrm{Si}$ cell is twice the volume of $\mathrm{SiC}$ cell. The length of all bonds decreases by $20 \%$, namely from $2.35 \mathrm{~nm}$ to $1.88 \mathrm{~nm}$. We note that five SiC crystal cells coincide with accuracy of $1 \%$ with four Si cells, and as a result, the atomic substitution reaction (3) occurs with minimal energy expenditures.

Process (3) proceeds layer-by-layer, i.e. at the same time several layers of pre-carbide silicon are being transformed into $\mathrm{SiC}$ with a shift of the film perpendicular to the substrate surface. This may explain the fact that $\mathrm{SiC}$ film is fairly uniform in thickness and does not contain noticeable voids. All voids are under $\mathrm{SiC}$ film, in the silicon. Since the process of substitution of atoms and "collapse" of Si volume occurs during the transformation of $\mathrm{Si}$ into SiC, any impurities located in Si shift under the film to the region of defective silicon. In a result a very pure $\mathrm{SiC}$ is being formed, which does not contain the phosphorus and boron dopants present in the original silicon. There is also no oxygen in the volume of the film.

Orientation of the film during reaction (1) is determined by the "old" crystalline structure of the original Si matrix, and not just by the substrate surface itself, as is usually the case in traditional film growth techniques. A temperature and a pressure of the gas are chosen so that the processes of nucleation of $\mathrm{SiC}$ and pores proceed simultaneously and at the same rate. Formation of elastic dipoles "carbon atom $\% \mathrm{Si} \mathrm{vacancy"} \mathrm{allows} \mathrm{one} \mathrm{to} \mathrm{obtain} \mathrm{high-qual-}$ ity silicon carbide films [1-6]. One of the most important properties of nano-SiC synthesized by the atomic substitution method is the unique possibility to grow not only cubic (3C-SiC), but also a number of hexagonal $\mathrm{SiC}$ polytypes such as the rare $2 \mathrm{H}$ $\mathrm{SiC}$ polytype, $6 \mathrm{H}-\mathrm{SiC}$ polytype and $4 \mathrm{H}-\mathrm{SiC}$ polytype [3,8-11]. Recently formation of a new, previously unknown, trigonal $\mathrm{SiC}$ phase was discovered [12]. This phase is being formed at the earliest stages of the substitution reaction (1).

Silicon carbide grown by atomic substitution differs from both bulk monocrystalline silicon carbide and silicon carbide grown on silicon by standard growth methods. This difference is associated with two features of the growth of $\mathrm{SiC}$ by this method. The first feature is the formation of dilatation dipoles mentioned above. The second feature is connected with the fact that right after the formation of dilatation dipoles during the process of transformation of 
"pre-carbide" silicon into silicon carbide, its shrinkage occurs. This shrinkage leads to a strong elastic compression of the subsurface material of the silicon substrate. At the same time, a part of silicon, both from "pre-carbide" silicon, and from the surface of the substrate itself is being "ejected" to the outside. As a result, both $\mathrm{SiC}$ and the surface layer of $\mathrm{Si}$ are compressed. Already after the transformation of $\mathrm{Si}$ into $\mathrm{SiC}$, but still at the growth stage ("ripening stage"), the silicon substrate may not stretch the SiC film, as in the usual methods of $\mathrm{SiC}$ growth, but rather compress it. This is due to the fact that the five crystalline cells of SiC practically coincide with the four crystalline cells of $\mathrm{Si}$ and which are only slightly smaller in size. This leads to the compression of $\mathrm{SiC}$. As a result, silicon vacancies are being formed in the silicon sublattice (these are no longer associated with dilatation dipoles), while in usual growth methods, on the contrary, the film is usually enriched with $\mathrm{Si}$. When growth is conducted by the atomic substitution method, surface of $\mathrm{SiC}$ film is enriched with carbon. Carbon under the action of elastic stresses is being shifted towards silicon vacancies located in the silicon sublattice. At this stage the elastic energy relaxes $[6,13,14]$ and the charge states of the surface change [15]. As a result, on the basis of an ensemble of dilatation dipoles, clusters are being formed, which we called carbon-vacancy clusters $[3,10,14]$. More precisely, carbon-vacancy clusters are being formed already at the final stage of the transformation of $\mathrm{Si}$ into $\mathrm{SiC}$. Their formation is associated with the initially existing dilatation dipoles, but, in general, their origin is of a different nature. It is associated with the effect of shrinkage of $\mathrm{SiC}$, as well as the effect of ascending diffusion caused by elastical compression during the growth of $\mathrm{SiC}$ on $\mathrm{Si}$ [13]. The formation of carbon-vacancy structures will be particularly intensive on the Si vicinal surfaces in the process of its conversion to SiC. Experimentally, the formation of these structures was found in a series of studies using methods of ellipsometry, IR spectroscopy and X-ray diffractometry $[10,16,17]$. It can be said that silicon carbide grown by atomic substitution method is not a purely cubic or pure hexagonal polytype. It is highly compressed in one direction and stretched in other direction. As a result of transformation, as shown in a series of papers $[12,18]$ and, as we already mentioned above, its symmetry changes, and it turns into $\mathrm{SiC}$ crystallizing into a trigonal phase.

Above, we said that elastic dipoles $C-V_{\mathrm{Si}}$ are always located perpendicular to the [111] direction and lie in the $(\overline{1} 10)$ plane, regardless of the initial crystallographic orientation of the Si substrate. These are the (111) faces that are formed primarily in the process of SiC synthesis by the atomic substitution method. Therefore, if there are steps on the $\mathrm{Si}$ vicinal surface and they are not (111) faces, then in the process of transformation into $\mathrm{SiC}$, (111) faces or $(\overline{1} 10)$ facets are necessarily being formed. An important factor is also the priority evaporation of silicon during the growth of such steps and, accordingly, the enrichment of the stepped surface with carbon as compared with the singular surface.

Since the SiC films are quite thin, several tens of nanometers in thickness (maximum $200 \mathrm{~nm}$ ), we will call this silicon carbide nanoscale $\mathrm{SiC}$ to distinguish these films from $\mathrm{SiC}$ films grown by standard methods.

In connection with the development of the atomic substitution method for growth of $\mathrm{SiC}$, a natural question arises. Is it possible to grow epitaxial SiC layer in a similar way on substrates of other materials, and not only on silicon? Based on the theoretical principles of [1-3], there are no physical obstacles for this. To obtain the epitaxial SiC, it is sufficient to apply an epitaxial layer of silicon (Si) whose thickness we determine below, on a substrate, the melting point of which should at least be above $1100^{\circ} \mathrm{C}$, at which reaction (1) begins to occur at a noticeable rate. Next, this substrate should be treated in $\mathrm{CO}$ gas or a mixture of $\mathrm{CO}$ gas and silane $\left(\mathrm{SiH}_{4}\right)$ according to reaction (1) in a reactor specially designed for this process [4]. After that, the surface will be covered with the $\mathrm{SiC}$ layer. If the initial silicon layer is epitaxial, then the $\mathrm{SiC}$ film formed as a result of the transformation of Si will also be epitaxial. If the $\mathrm{Si} \mathrm{layer} \mathrm{is} \mathrm{amorphous} \mathrm{or} \mathrm{polycrystalline,} \mathrm{then}$ the $\mathrm{SiC}$ layer will also be polycrystalline. Thus, the method of SiC growth proposed in [1-4] opens up unprecedented conditions for coating various materials with $\mathrm{SiC}$ layer. This may be the production of various kinds of semiconductors, semiconductor substrates for different purposes, heat-resistant and chemically resistant coatings, different types of mirrors and optical coatings based on $\mathrm{SiC}$, etc.

In this regard, the purpose of this study is to experimentally prove the basic fundamental principles developed in [1-3] not only with regard to the growth of SiC on Si substrates, but also with regard to transformation of Si deposited on other substrates into $\mathrm{SiC}$ by the method of atomic substitution. In this paper, we will show that this method can be used to grow epitaxial silicon carbide on a sapphire $\left(\mathrm{Al}_{2} \mathrm{O}_{3}\right)$. 


\subsection{The current state of the art and problems of growth of SiC epitaxial films on sapphire}

Researchers have been engaged in the growth of epitaxial SiC on sapphire for a long time. So, back in [19], $\beta$-SiC films were mechanically transferred to sapphire substrates in order to create an optical waveguide. For a better conjugation of sapphire and silicon carbide lattices, an AIN layer is usually applied as a buffer layer between sapphire and silicon carbide. The authors of [20] showed that preliminary deposition of the AIN buffer layer significantly improves the quality of $\mathrm{SiC}$ film and leads to the formation of epitaxial $6 \mathrm{H}-\mathrm{SiC}$ on sapphire. In paper [21], a polycrystalline $\mathrm{SiC}$ film was deposited on "C" sapphire plane by CVD method in ultrahigh vacuum to further obtain graphene layers on insulating sapphire substrate. In [22], CVD at low pressure (LPCVD method) was used to grow SiC polycrystalline films on the sapphire in order to create optical temperature sensors based on FabryPerot interferometric method. The authors of the study [23] used MBE method to grow $4 \mathrm{H}-\mathrm{SiC}$ epitaxial films on a sapphire substrate with the predeposited AIN layer and $\mathrm{C}^{60}$ fullerenes as a carbon source. The full-width of the rocking curves at halfmaximum (FWHM) was $\omega_{\theta} \approx 0.24^{\circ}$, which is a very good result. However, this method involves sophisticated MBE technology, and also requires the preliminary deposition of the additional AIN layer on the sapphire. Later, in [24], using the AIN as the buffer layer and pretreatment of the sapphire or sapphire substrate with the AIN layer in a hydrogen stream, and then in a propane stream $\left(\mathrm{C}_{3} \mathrm{H}_{8}\right)$, the authors were able to grow $2 \mathrm{H}-\mathrm{SiC}$ polytype by MOCVD method. By analysing TEM images in this article one can conclude that in some areas of the film quality of $2 \mathrm{H}-\mathrm{SiC}$ layer was very high, and the conjugation between $2 \mathrm{H}-\mathrm{SiC}$ and AIN layers was very good. However, based on the data obtained from rocking curves (Fig. 1, data from [24]), one can conclude that the best samples had the value of FWHM $\omega_{\theta} \approx 40$ arcmin. On average, the best films had FWHM $\omega_{\theta} \approx 80$ arcmin, i.e. were closer to a texture rather than to an epitaxy. Therefore, in our opinion, the data given in [24] is very contradictory. The authors of the study [25] grew 3C-SiC layers on the (0001) plane of the sapphire using MOCVD method. The grown 3C-SiC films had the thickness of 5-7 $\mu \mathrm{m}$. Unfortunately, nothing definite can be said about the quality of the grown layers, since the authors of the work have not provided the results on the halfwidths of the rocking curves, i.e. FWHM $\omega_{\theta}$ values.
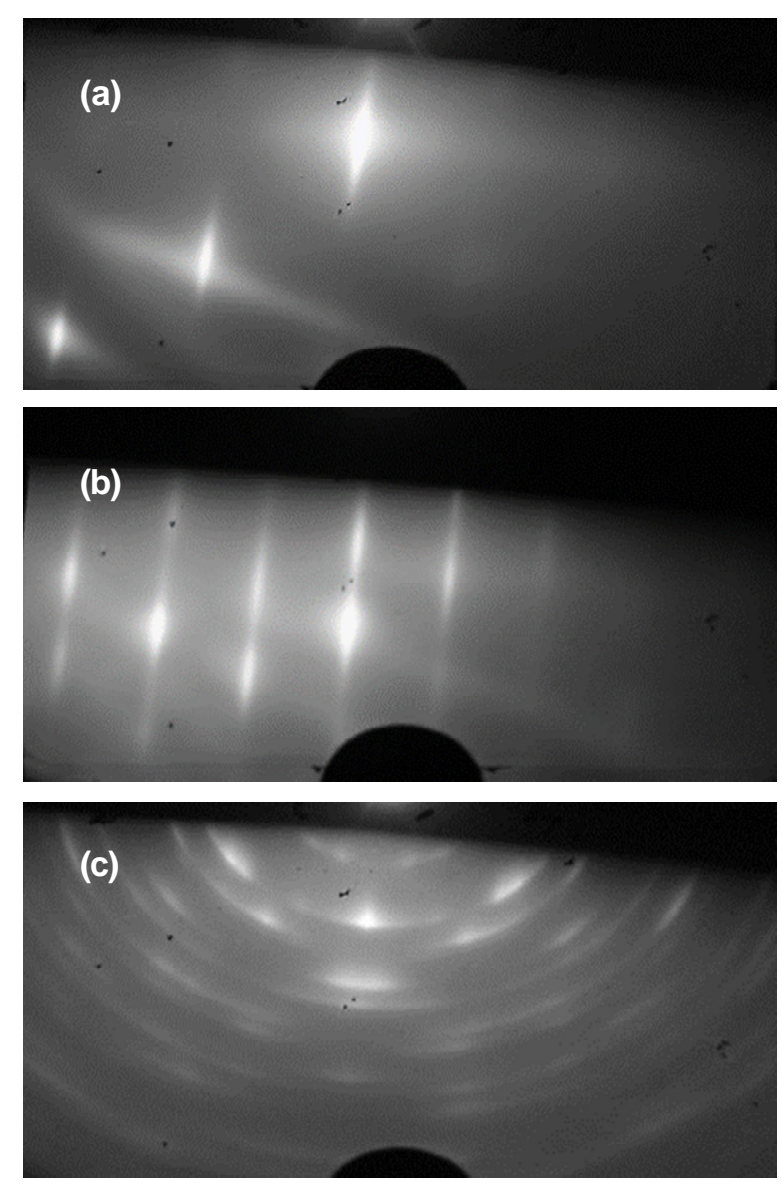

Fig. 1. RHEED patterns of $\mathrm{Si}$ samples, grown on $\mathrm{Al}_{2} \mathrm{O}_{3}$; (a) $\mathrm{Si}(100) / \mathrm{Al}_{2} \mathrm{O}_{3}$ on r-plane (1 120$)$ sapphire Fab-1-R-plane; (b) Si(100)/ $/ \mathrm{Al}_{2} \mathrm{O}_{3}$ on r-plane sapphire Fab-2-R-plane; (c) $\mathrm{Si}(111) / \mathrm{Al}_{2} \mathrm{O}_{3}$ on c-plane (0001) sapphire Fab-2-C-plane.

XRD spectra evidence that peaks corresponding to the $3 \mathrm{C}$-SiC layer are quite wide, which means that the films were most likely polycrystalline. Moreover, multiple dislocations (or twin grains) are clearly visible on SEM images of the cross-sections of 3C$\mathrm{SiC}$ films. This is quite typical, since there is a large difference of about $12 \%$ between $3 \mathrm{C}$-SiC lattice parameter and one of the sapphire on (0001) plane. Note that there is a patent dated May 12, 2012 [26] which describes a method for growth of epitaxial $\mathrm{SiC}$ layer on sapphire involving MOCVD in ultrahigh vacuum (about $10^{-6}$ Torr). SiC films in this case were about $90 \mathrm{~nm}$ thick. The paper [27] describes studies on the growth of $3 \mathrm{C}-\mathrm{SiC}$ on the sapphire from a melt.

Thus, at present, interest in the growth of epitaxial $\mathrm{SiC}$ films on a sapphire is constantly growing. Indeed, high hardness, inertness to a chemically active media, excellent insulating properties ensure good use of the sapphire substrates with a layer of such wide-bandgap semiconductor as $\mathrm{SiC}$ in mi- 
croelectronics, as well as in manufacturing of various types of detectors and sensors. In addition, one can grow graphene layers on the insulating sapphire substrate using such $\mathrm{SiC}$ layer.

The purpose of this study is to develop a new method for growth of $\mathrm{SiC}$ films on the sapphire, based on the method of atomic substitution, discovered in [1-4] and to study growth mechanisms and structure of $\mathrm{SiC}$ layers on sapphire. To solve this issue, in accordance with the basic principles of the method of atomic substitution [1-4], it is necessary firstly to grow a layer of epitaxial $\mathrm{Si}$ on the surface of the sapphire substrate, and then to convert it into $\mathrm{SiC}$ using reaction (1). Below we describe in detail and sequentially stages of the growth of $\mathrm{SiC}$ epitaxial films by substitution of atoms on the sapphire.

\section{SEQUENTIAL STAGES OF GROWTH OF EPITAXIAL SIC FILMS BY THE METHOD OF ATOMIC SUBSTITUTION ON A SAPPHIRE}

\subsection{Growth of epitaxial Si films on a sapphire with orientation of $\mathrm{Si}$ layer of (100) and (111)}

The structure of "silicon-on-sapphire" (SOS) is a thin layer of single-crystal silicon formed by heteroepitaxy on a dielectric substrate of synthetic sapphire (leucosapphire, $\alpha-\mathrm{Al}_{2} \mathrm{O}_{3}$ ). Physicochemical interaction between the silicon and the sapphire at the stage of formation of a transition layer creates a strong bond at the interface between the layer and the substrate, which ensures sufficient mechanical strength of the heteroepitaxial structure. Excellent insulating properties, sufficient thermal conductivity and transparency of the sapphire substrate in the ultraviolet range allows SOS structures to be used in microelectronics (radiation-resistant integrated circuits (ICs), logic converters of the combinative type, high-voltage high-speed rectifiers), in manufacturing of detectors and sensors (photo detectors and resistive integrated circuits), as well as in manufacturing of microelectromechanical systems (MEMS) and nanoelectromechanical systems (NEMS) [28-30]. Nowadays the SOS-structures obtained by the method of epitaxy (both MBE and CVD) are considered as the base material for manufacturing of high-frequency ICs with an ultra-thin instrument layer of silicon. These devices have a high degree of integration and increased resistance to external destabilizing factors, such as temperature, pressure and radiation, which ensure the priority of using electronics on the SOS-structures in the atomic, space, military, and other industries [28,31]. In addition, SOS-structures with a thin (up to 600 $\mathrm{nm}$ ) epitaxial silicon layer can be used as a base substrate for the formation of SiGe compositions and growth of epitaxial Ge layers. It is known that manufacturing of transistors with high electron mobility (MODFETs) on SiGe requires isolation of elements on the substrate due to need to minimize leakage currents [32]. Use of Si layers on the sapphire virtually eliminates leakage currents and parasitic capacitances between MODFETs, which along with the possibility of integrating it into silicon technology makes such structures very promising.

However, there are barriers to widespread use of SOS-structures, including: high density of structural defects in growing SOS-layers and complexity of optimization of the epitaxial growth process. For heteroepitaxial SOS-structures, the lattice mismatch of silicon and sapphire in lateral direction can reach up to $12.5 \%$ if the epitaxial layer of $\mathrm{Si}(111)$ is being formed on the c-plane sapphire (0001) substrate and about $6 \%$ in case of growth of $\mathrm{Si} \mathrm{(100)}$ on r-plane sapphire $(1 \overline{1} 20)$. The lattice mismatch and the difference in thermal expansion coefficients of silicon and sapphire lead to the emergence of mechanical stresses in epitaxial layers of silicon and, as a consequence, to the formation of misfit dislocations. The vicinal surface of the sapphire can contain a large number of centers of formation of structural disorders (centers of misorientation), from which diferent packaging defects and twin lamellae (microtwins) arise during the initial stages of growth $[28,29,32]$. Structural violations of the epitaxial silicon on the sapphire inevitably lead to degradation of electrical parameters, to increase in microroughness of the working surface and to decrease in mechanical strength of the layer. The process of gas-phase deposition of silicon on the sapphire substrate is significantly different from an autoepitaxial silicon process.

The growth of Si on the sapphire occurs according to the Stranski - Krastanov mechanism, i.e. at the initial stage of film growth, three-dimensional islands are being formed. The deposited silicon can chemically interact with the sapphire surface, contaminating the growing islands, and thereby increasing their mutual disorientation and the defectiveness of the formed layer. Optimal conditions for the epitaxial growth process determine the structural characteristics of the SOS, which, in turn, are a key parameter for most applications.

In this work, heteroepitaxial silicon layers with a thickness of 300-600 nm were grown on sapphire 

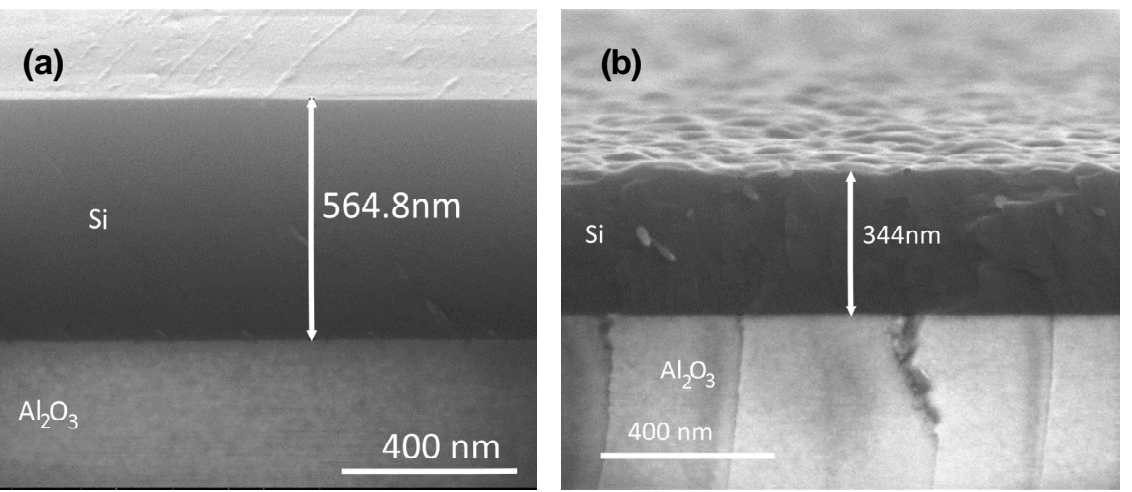

Fig. 2. Typical SEM images of the cross-section and the surface of $\mathrm{Si}(100)$ and $\mathrm{Si}$ (111) films grown on $\mathrm{Al}_{2} \mathrm{O}_{3}$; (a) cross-section and surface of the $\mathrm{Si}(100) / r$-plane $\mathrm{Al}_{2} \mathrm{O}_{3}$ structure; (b) cross-section and surface of the $\mathrm{Si}(111) / \mathrm{c}$-plane $\mathrm{Al}_{2} \mathrm{O}_{3}$ structure.

substrates of c-plane and r-plane orientation. The process of fabrication of the structures was carried out using the industrial vertical epitaxial reactor PE2061S of LPE (Italy). A working pressure of about 1 atm was maintained in the reactor chamber, and dried $\mathrm{H}_{2}$ with water vapor content of $<5 \mathrm{ppb}$ was used as a carrier gas. In the growth process silicon layers were deposited on the sapphire from gas mixture of $\mathrm{SiH}_{4}$ and $\mathrm{H}_{2}$ at volume ratio of $\mathrm{SiH}_{4}: \mathrm{H}_{2}$ of about $0.01: 1$. In order to achieve a high structural quality and the lowest possible roughness of Si layers of different orientations, technological methods described in detail in $[33,34]$ were applied. The growth of $\mathrm{Si}$ on the r-plane $(1 \overline{1} 20)$ sapphire was carried out on two types of sapphire substrates from different manufacturers.

We denote these substrates by the following designations, namely, Fab-1-R-plane and Fab-2-Rplane, where the letter $R$ denotes that in this case we used the r-plane for research $(1 \overline{1} 20)$. Si $(100) /$ $\mathrm{Al}_{2} \mathrm{O}_{3}$ layers on the r-plane $(1 \overline{1} 20)$ sapphire had a high structural quality of epitaxial Si with a full width of the rocking curve at half maximum $\mathrm{FWHM} \leq 0.3^{\circ}$. RMS of the working surface did not exceed $1 \pm 0.5$ $\mathrm{nm}$.

For the growth of Si on c-plane (0001) sapphire, we used the sapphire of the same manufacturer as the Fab-2-R-plane substrate. Let's designate it as Fab-2-C-plane. $\mathrm{Si}(111) / \mathrm{Al}_{2} \mathrm{O}_{3}$ on c-plane (0001) sapphire structure grown as a textured crystal with an ordered distribution of Si crystallites of (111) orientation. RMS of this structure did not exceed $5 \pm 0.5$ $\mathrm{nm}$.

Fig. 1 shows patterns of reflection high-energy electron diffraction (RHEED) taken from $\mathrm{Si}$ samples grown on r-plane (1 1 20) Fab-1-R-plane sapphire and Fab-2-R-plane sapphire (Figs. 1a and 1b), and from one grown on c-plane (0001) sapphire Fab-2-C-plane (Fig. 1c).
It is clearly seen from these data that $\mathrm{Si}(100)$ films grown on the Fab-1-R-plane and Fab-2-R-plane samples are epitaxial, well oriented, as evidenced by the nature of the reflexes in Figs. $1 a$ and $1 b$. The Si film grown on the sample Fab-1-R-plane approaches in quality to a single crystal, since its electron diffraction pattern (Fig. 1a) contains Kikuchi lines indicating high crystalline perfection. The $\mathrm{Si}$ film grown on the Fab-2-C-plane sample on $\mathrm{Si}(111) / \mathrm{Al}_{2} \mathrm{O}_{3}$ (fig.1c) is a texture.

Fig. 2 shows typical SEM micrographs of crosssection of the samples $\mathrm{Si}(100)$ grown on r-plane (1 1 20) sapphire Fab-1-R-plane and Fab-2-R-plane, and of the sample Si(111) grown on c-plane (0001) sapphire Fab-2-C-plane (Fig. 1b). SEM images of the cross-section of the $\mathrm{Si}(100)$ films grown on the Fab-1-R-plane and Fab-2-R-plane samples are practically indistinguishable from each other, therefore we have shown only one micrograph (Fig. 2a). The figure clearly indicates that the $\mathrm{Si}(111)$ structure grown on c-plane $\mathrm{Al}_{2} \mathrm{O}_{3}$ is less dense, looser than the $\mathrm{Si}(100)$ structure grown on $\mathrm{r}$-plane $\mathrm{Al}_{2} \mathrm{O}_{3}$. The $\mathrm{Si}$ (111) $/ \mathrm{Al}_{2} \mathrm{O}_{3} \mathrm{C}$-plane interface contains dislocations and other defects.

Fig. 3 shows $X$-ray diffraction spectra (XRD) from the original $\mathrm{Si}(100)$ and $\mathrm{Si}(111)$ layers grown on sapphire. Fig. 3a shows the typical diffractogram from the $\mathrm{Si}(100) / \mathrm{Al}_{2} \mathrm{O}_{3}$ structure grown on r-plane sapphire Fab-2-R-plane, and on r-plane sapphire Fab1-R-plane. Fig. $3 b$ shows the diffractogram of the $\mathrm{Si}(111) / \mathrm{Al}_{2} \mathrm{O}_{3}$ structure grown on c-plane sapphire Fab-2-C-plane.

As can be seen in Fig. 3, a peak from the sapphire substrate is present in both diffractograms. The $\mathrm{Si}(100) / r$-plane $\mathrm{Al}_{2} \mathrm{O}_{3}$ structure is strained; therefore the forbidden reflection of $\mathrm{Si}(200)_{\mathrm{f}}$ is observed from the silicon $\mathrm{Si}$ (100) layer. The diffractogram of the sample $\mathrm{Si}(111) / \mathrm{c}$-plane $\mathrm{Al}_{2} \mathrm{O}_{3}$ was measured in the $\theta / 2 \theta$ symmetric geometry. In this diffractogram, 

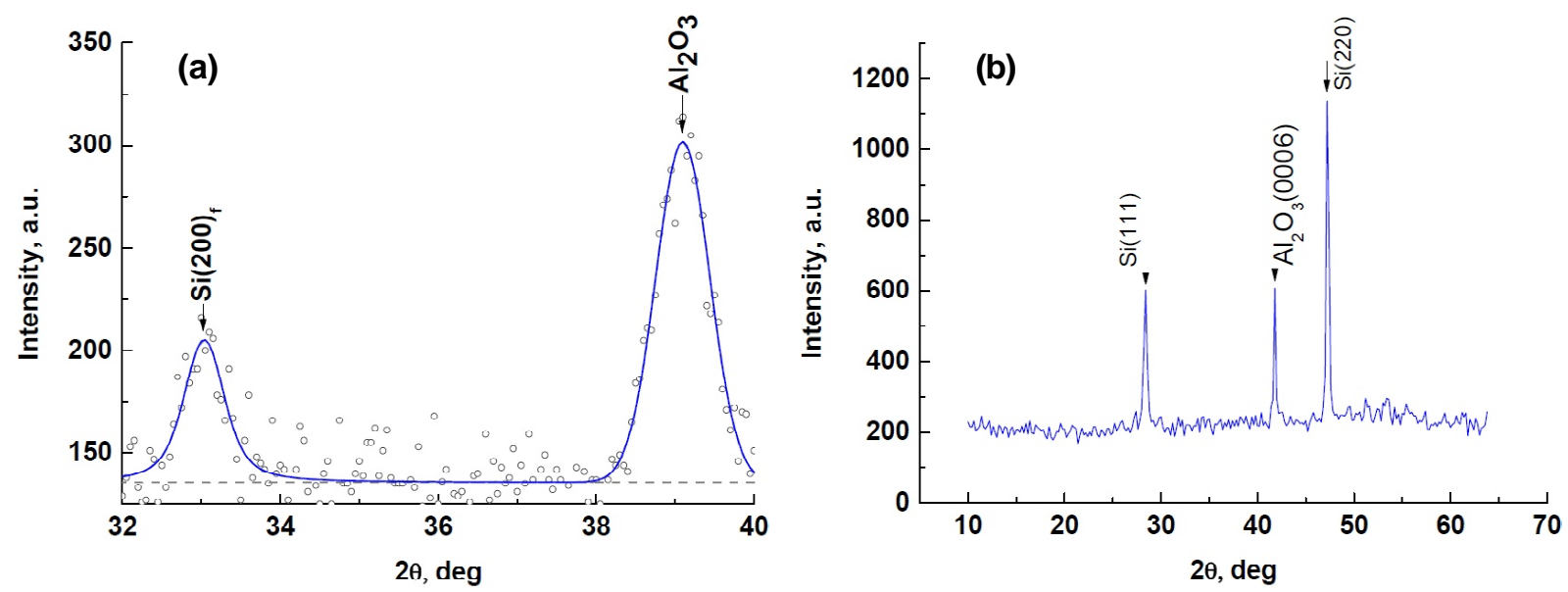

Fig. 3. X-ray diffractograms of the initial layers of $\mathrm{Si}(100)$ and $\mathrm{Si}(111)$ grown on $\mathrm{Al}_{2} \mathrm{O}_{3} ;$ (a) typical diffractogram of the $\mathrm{Si}(100) /$ r-plane $\mathrm{Al}_{2} \mathrm{O}_{3}$ structure on Fab-2-R-plane and Fab-1-R-plane; (b) diffractogram of the $\mathrm{Si}(111) /$ c-plane $\mathrm{Al}_{2} \mathrm{O}_{3}$ structure on Fab-2-C-plane sapphire.

there is a peak from the substrate $\mathrm{Al}_{2} \mathrm{O}_{3}(0006)$, corresponding to a given substrate orientation (0001). The grown silicon film is polycrystalline and textured. The main orientations of silicon crystals presented in the layer correspond to peaks [220] and [111].

\subsection{Conversion of Si epitaxial films on a sapphire to $\mathrm{SiC}$ epitaxial films on a sapphire}

After growth of the Si films on a sapphire, in order to transform them into $\mathrm{SiC}$ layers, it is needed to subject the resulting SOS-structures to chemical exposure to $\mathrm{CO}$ gas via reaction (1). Before this, however, it is necessary to remove a layer of silicon oxide from their surface, which can be formed due to interaction of Si with atmospheric oxygen. Otherwise, the chemical reaction between $\mathrm{CO}$ and $\mathrm{Si}$, on the surface of which $\mathrm{SiO}_{2}$ is located, will proceed differently compared with reaction (1). In this case, dilatation dipoles will not form, and the SiC film will grow polycrystalline. Thus, to obtain the SiC epitaxial layer, before carrying out the reaction (1), it is necessary to prepare the Si surface for SiC growth, namely, to obtain a smooth surface at an atomic scale and to remove even nanolayers of silicon dioxide from the surface of the silicon. In addition, it is necessary to passivate the surface of the Si layer by hydrogen in order to prevent its possible rapid oxidation during storage and transportation. The method of preparation of Si surface and its passivation was specially developed for the growth of SiC in [35] and described in detail in [36].

After the passivation of Si films, they were annealed in the reactor specially designed for SiC synthesis [4], in an atmosphere of a mixture of carbon monoxide $(\mathrm{CO})$ and silane $\left(\mathrm{SiH}_{4}\right)$ gases according to reaction (1). Note that in [3], it was proved that in the process of synthesys of SiC by the method of atomic substitution pores of shrinkage are being formed simultaneously with the nucleation of $\mathrm{SiC}$ layer. Their formation is a consequence of the difference in the volumes per cell in the SiC film and in the $\mathrm{Si}$ substrate. The formation of shrinkage pores is an undesirable process. Therefore, in [3], it was proposed to add gaseous silane $\left(\mathrm{SiH}_{4}\right)$ to the main $\mathrm{CO}$ gas. $\mathrm{SiH}_{4}$ addition to $\mathrm{CO}$ in the right proportion results in complete healing of shrinkage pores. At the same time, the $\mathrm{SiC}$ surface becomes smooth.

To compare the results of the growth of $\mathrm{SiC}$ films on $\mathrm{Si} / \mathrm{Al}_{2} \mathrm{O}_{3}$ with the growth of $\mathrm{SiC}$ films on silicon single-crystal substrates under standard conditions selected by long-term studies $[3,4,15]$, we synthesized samples under conditions whereby SiC films on single-crystal Si were single-crystal, highly oriented structures. So, we transformed Si (100) films on sapphire into $\mathrm{SiC}$ layers at a temperature $T=$ $1290^{\circ} \mathrm{C}$. The total pressure of the gas mixture (CO $\left.+\mathrm{SiH}_{4}\right)$ was $133 \mathrm{~Pa}$. The $\mathrm{CO}$ gas flow was $12 \mathrm{sccm}$. The $\mathrm{SiH}_{4}$ gas flow was $3.5 \mathrm{sccm}$. Synthesis time was $15 \mathrm{~min}$. The growth of $\mathrm{SiC}$ films from $\mathrm{Si}$ (111) on sapphire was also carried out in a mixture of $\mathrm{CO}$ and $\mathrm{SiH}_{4}$ gases. The growth temperature, growth time, and gas flow rates were similar to the growth of $\mathrm{SiC}$ films from $\mathrm{Si}(100)$. Only the total pressure of the gas mixture $\left(\mathrm{CO}+\mathrm{SiH}_{4}\right)$ differed. In this case, we grew films at a total gas pressure of $67 \mathrm{~Pa}$.

After the formation of $\mathrm{SiC}$, the samples were studied by scanning electron microscopy, confocal Raman microscopy, ellipsometry, X-ray diffraction, 

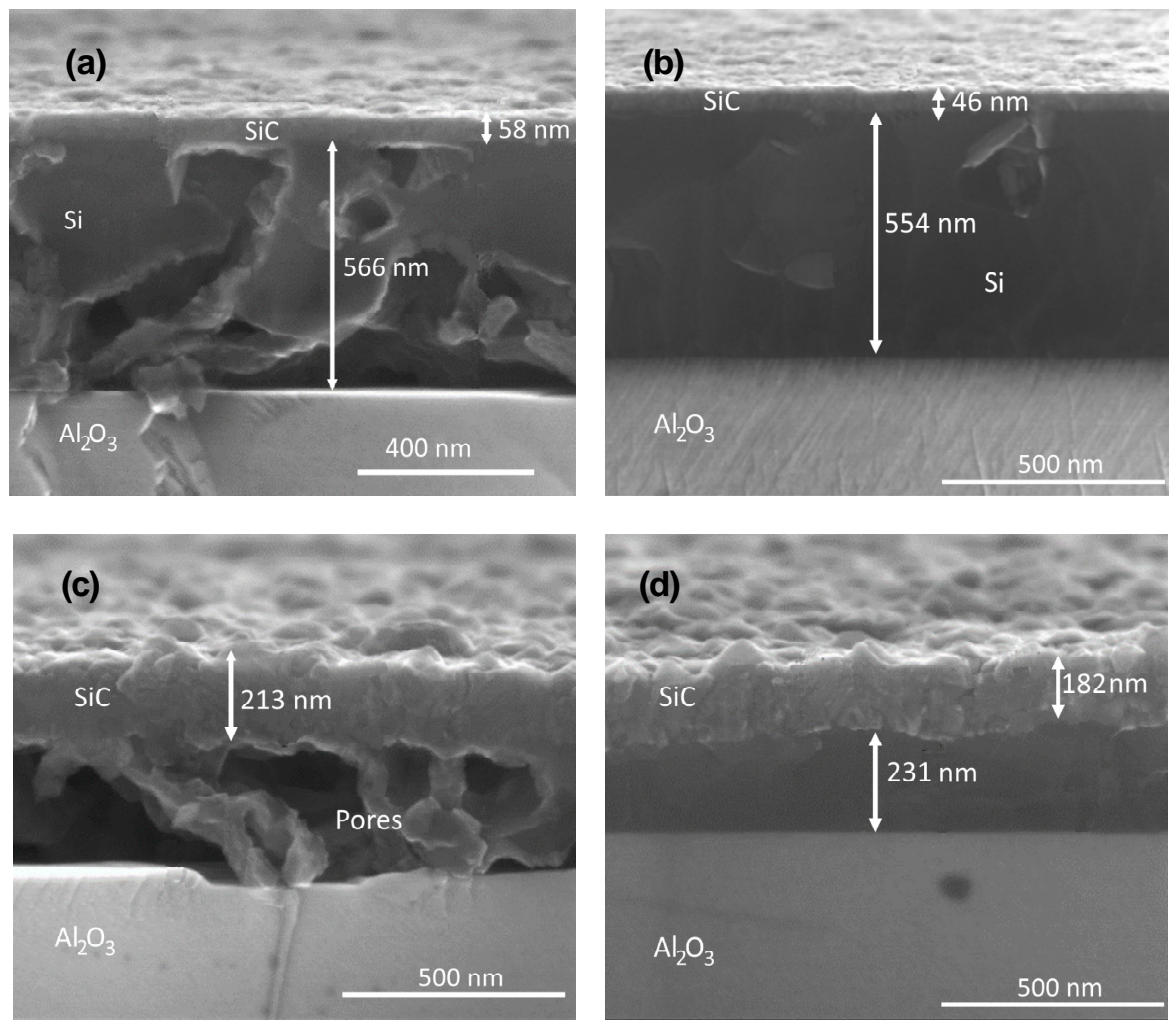

Fig. 4. SEM images of the cross-sections of different areas of the $\mathrm{SiC} / \mathrm{Si}(100)$ and $\mathrm{SiC} / \mathrm{Si}$ (111) samples grown on $\mathrm{Al}_{2} \mathrm{O}_{3}$; (a) cross-section of a region containing pores, coated with a $\mathrm{SiC}$ layer in the $\mathrm{SiC} / \mathrm{Si}(100) /$ r-plane (1 1 20) $\mathrm{Al}_{2} \mathrm{O}_{3}$ structure, grown on Fab-2-R-plane sapphire; (b) cross-section of an area practically free from pores in the $\mathrm{SiC} / \mathrm{Si}(100) / r$-plane $\left(1 \overline{1}_{2} 20\right) \mathrm{Al}_{2} \mathrm{O}_{3}$ structure grown on Fab-1-R-plane sapphire; (c) cross-section of a region containing pores, coated with a SiC layer on the $\mathrm{SiC} / \mathrm{Si}(111) / \mathrm{c}$-plane $\mathrm{Al}_{2} \mathrm{O}_{3}$ structure; (d) cross-section of an area practically free from pores on the $\mathrm{SiC} / \mathrm{Si}(111) / \mathrm{c}-$ plane $\mathrm{Al}_{2} \mathrm{O}_{3}$ structure.

and reflection high-energy electron diffraction (RHEED).

\section{STRUCTURAL AND MORPHOLOGICAL FEATURES OF THE FORMATION OF SIC FILMS BY CONVERSION OF Si FILMS ON SAPPHIRE}

Fig. 4 shows SEM images of the cross-sections of different areas of the $\mathrm{SiC} / \mathrm{Si}(100)$ and $\mathrm{SiC} / \mathrm{Si}(111)$ samples on $\mathrm{Al}_{2} \mathrm{O}_{3}$. Fig. 4a shows the cross-section of the region containing pores in $\mathrm{Si}$, covered with a $\mathrm{SiC}$ layer on the $\mathrm{SiC} / \mathrm{Si}(100) / \mathrm{r}$-plane $(1 \overline{1} 20) \mathrm{Al}_{2} \mathrm{O}_{3}$ structure grown on Fab-2-R-plane sapphire. Fig. 4b shows the cross-section of the region containing pores in $\mathrm{Si}$, covered with a $\mathrm{SiC}$ layer on the $\mathrm{SiC} /$ $\mathrm{Si}(100) / r$-plane $(1 \overline{1} 20) \mathrm{Al}_{2} \mathrm{O}_{3}$ structure grown on a Fab-1-R-plane sapphire. It is clearly seen that the layer depicted in Fig. 4a is on average slightly thicker than the SiC layer, which cross-section is shown in Fig.4b. It is more loose and contains more pores. Analysis of a large number of SEM micrographs taken from different surface regions of these sam- ples showed that in the $\mathrm{SiC} / \mathrm{Si}(100) / r$-plane $(1 \overline{1} 20) \mathrm{Al}_{2} \mathrm{O}_{3}$ sample grown on Fab-1-R-plane sapphire there are places with a large number of pores, but in general, the density of pores in the $\mathrm{SiC} / \mathrm{Si}$ $(100) / r$-plane $(1 \overline{1} 20) \mathrm{Al}_{2} \mathrm{O}_{3}$ sample grown on the Fab1-R-plane sapphire is significantly less than the density in the sample grown on sapphire Fab-2-Rplane.

The $\mathrm{SiC} / \mathrm{Si}(111) / \mathrm{c}$-plane $\mathrm{Al}_{2} \mathrm{O}_{3}$ sample, as follows from Fig. 4c, is looser and contains a large number of pores, although it also contains certain regions in which pores are practically absent (Fig. $4 d$ ). It is interesting to note that the more "loose", less crystalline and closer to the texture the structure of the original silicon on sapphire, the deeper $\mathrm{CO}$ gas penetrates into the Si layer. So, in Fig. 4c one can see that the c-plane, i.e. the sapphire (0001) plane begins to be etched during the synthesis of SiC. In our opinion, the etching may be due to a chemical reaction like:

$$
\begin{aligned}
& \mathrm{Al}_{2} \mathrm{O}_{3}(\text { cr })+\mathrm{CO}(\text { gas })=\mathrm{Al}_{2} \mathrm{O}(\text { gas })+ \\
& \left.\mathrm{Al}+\mathrm{CO}_{2} \text { (gas }\right),
\end{aligned}
$$



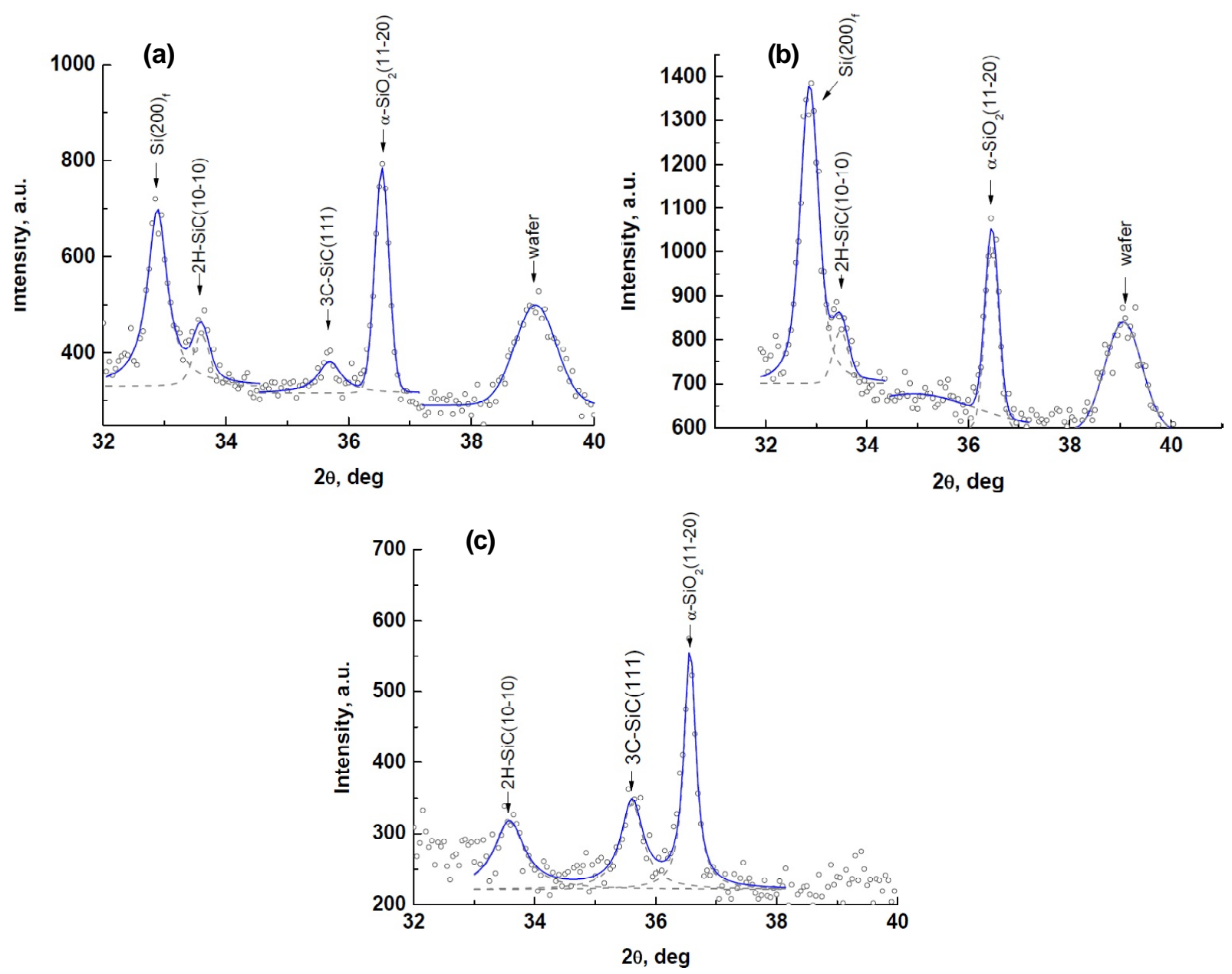

Fig. 5. X-ray difractograms of $\mathrm{SiC}$ samples, grown on $\mathrm{Si}(100) / \mathrm{Al}_{2} \mathrm{O}_{3} \mathrm{r}$-plane and $\mathrm{Si}(111) / \mathrm{Al}_{2} \mathrm{O}_{3} \mathrm{c}$-plane; (a) $\mathrm{SiC} / \mathrm{Si}(100)$ on sapphire Fab-2-R-plane; (b)" $\mathrm{SiC} / \mathrm{Si}(100)$ on sapphire Fab-1-R-plane; (c) $\mathrm{SiC} / \mathrm{Si}(111)$ on sapphire Fab-2-C-plane.

which, as shown in [37], can occur at a temperature of the order of $T \sim 1280{ }^{\circ} \mathrm{C}$. The $\mathrm{CO}_{2}$ gas released during the reaction will react also with $\mathrm{Si}$ at the $\mathrm{Si} / \mathrm{Al}_{2} \mathrm{O}_{3}$ interface and will again form $\mathrm{SiC}$, but with an admixture of quartz (crystalline $\mathrm{SiO}_{2}$ ) in accordance with reaction (5)

$$
\mathrm{CO}_{2}(\text { gas })+2 \mathrm{Si}=\mathrm{SiC}+\mathrm{SiO}_{2}(c r) \text {. }
$$

Moreover, according to [13,38], in the presence of $\mathrm{CO}$ and $\mathrm{CO}_{2}$ gases, a series of other reactions are possible, which we do not consider here. Obviously, at the temperature at which SiC is synthesized, silicon oxide can appear both in the form of silica glass and in the form of crystalline quartz. It is quite possible that inside ordered phases $(\mathrm{Si}, \mathrm{SiC}$, $\left.\mathrm{Al}_{2} \mathrm{O}_{3}\right) \mathrm{SiO}_{2}$ is being grown in crystalline form, which we actually found in XRD spectra of $\mathrm{SiC}$ samples grown on $\mathrm{Si}(100) / \mathrm{Al}_{2} \mathrm{O}_{3}$ and $\mathrm{Si}(111) / \mathrm{Al}_{2} \mathrm{O}_{3}$ and which are shown in Fig. 5. We note that a specific analysis of the formation of quartz oxide is not the topic of this work and we will not dwell on it anymore.
Fig. 5 shows XRD taken from the $\mathrm{SiC} / \mathrm{Si}(100) /$ $\mathrm{Al}_{2} \mathrm{O}_{3}$ r-plane and $\mathrm{SiC} / \mathrm{Si}(111) / \mathrm{Al}_{2} \mathrm{O}_{3}$ c-plane samples grown on Fab-1-R-plane sapphire, Fab-2-Rplane sapphire and Fab-2-C-plane. In the difractogram of the $\mathrm{SiC}$ sample grown on $\mathrm{Si}(100) / \mathrm{r}$ plane $\mathrm{Al}_{2} \mathrm{O}_{3}$ Fab-2-R-plane, XRD peaks can be observed, the positions of which correspond to both $2 \mathrm{H}-\mathrm{SiC}$ and $3 \mathrm{C}-\mathrm{SiC}$ polytypes. In the difractogram of the $\mathrm{SiC}$ sample grown on $\mathrm{Si}(100) / \mathrm{r}$-plane $\mathrm{Al}_{2} \mathrm{O}_{3}$ Fab-1-R-plane, the XRD peak from the $3 \mathrm{C}$-SiC phase is absent. There are peaks of $2 \mathrm{H}-\mathrm{SiC}$ and $3 \mathrm{C}-\mathrm{SiC}$ phases on XRD spectra taken from the $\mathrm{SiC} / \mathrm{Si}(111)$ structure grown on sapphire Fab-2-C-plane. In all samples, a peak is observed, whose position corresponds to the $\alpha$-quartz phase. Note that in this case, we cannot confidently assert that during the conversion of $\mathrm{Si} / \mathrm{Al}_{2} \mathrm{O}_{3}$ to $\mathrm{SiC} / \mathrm{Al}_{2} \mathrm{O}_{3}$, a $2 \mathrm{H}-\mathrm{SiC}$ phase is being formed on sapphire. The XRD peak is quite "blurred". According to the data of [39], XRD peaks of other hexagonal polytypes are also located in

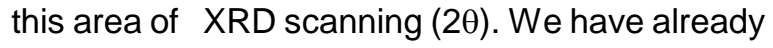


noted above $[3,8-11]$ that during the growth of $\mathrm{SiC}$ by the method of atomic substitution, $\mathrm{SiC}$ layers of different polytypes can be formed. Therefore, the formation of $2 \mathrm{H}-\mathrm{SiC}$ layers should not be surprising, since the physicochemical nature of the substitution method does not prohibit the formation of this phase. Moreover, as was shown above, on a non-cubic sapphire crystal (trigonal syngony) with an AIN layer, it is often the $2 \mathrm{H}-\mathrm{SiC}$ polytype that is being formed during the deposition of $\mathrm{SiC}$ [24].

As follows from the data in Fig. 5, the $\alpha$-quartz phase is being formed along with SiC. We associate its appearance with the occurrence of reactions (4) and (5), which take place when $\mathrm{SiC}$ grows on the sapphire. During the growth of $\mathrm{SiC}$ by the method of atomic substitution on pure $\mathrm{Si}$, the formation of $\alpha$-quartz was not observed under the given synthesis conditions. It should be noted that in the general case, according to calculations performed in $[13,38]$, the formation of silicon oxide can occur during transformation of Si into SiC.

Above, we noted that one of the fundamental stages of the chemical reaction (1) is the stage of formation of dilatation dipoles, which is the reaction (2) stage. These dipoles are located along the direction [111] in $\mathrm{Si}$. Therefore, even if it is not the silicon (111) plane which is in the reaction zone, but some another plane, for example, the (100) plane, then still during its transformation it will turn into $\mathrm{SiC}$ plane covered by a family of planes (facets) (111), or a system of facets having a hexagonal orientation (instead of the initial Si (100) plane) according to $[3,15]$. This is what we see in our case. Thus, the initial surface (100) of the sample, which $X R D$ spectra is shown in Fig. 3, turned into a family of (111) 3C-SiC and (10 $\overline{1} 1)$ surfaces. The same planes of hexagonal crystals are also being formed when $\mathrm{SiC}$ grows by the method of atomic substitution on $\mathrm{Si}(100)$ single-crystals, which was theoretically and experimentally proved in $[3,15]$.

The planes $(10 \overline{1} 1)$ are so-called semi-polar planes of hexagonal crystals [40]. The formation of such planes plays a crucial role in the growth of semipolar layers of such wide-bandgap semiconductors as AIN, GaN, and a number of other crystals with a hexagonal crystal lattice [40]. This means that technological improvement of the SiC-from-Si (100) growth method on sapphire, described in the present work, may lead to possibility of growth of device-quality semipolar AIN and GaN layers on an insulating substrate.

Fig. 6 demonstrates reflection high-energy electron diffraction (RHEED) patterns of SiC samples grown on $\mathrm{Si}(100) / \mathrm{Al}_{2} \mathrm{O}_{3}$ r-plane. We provided only
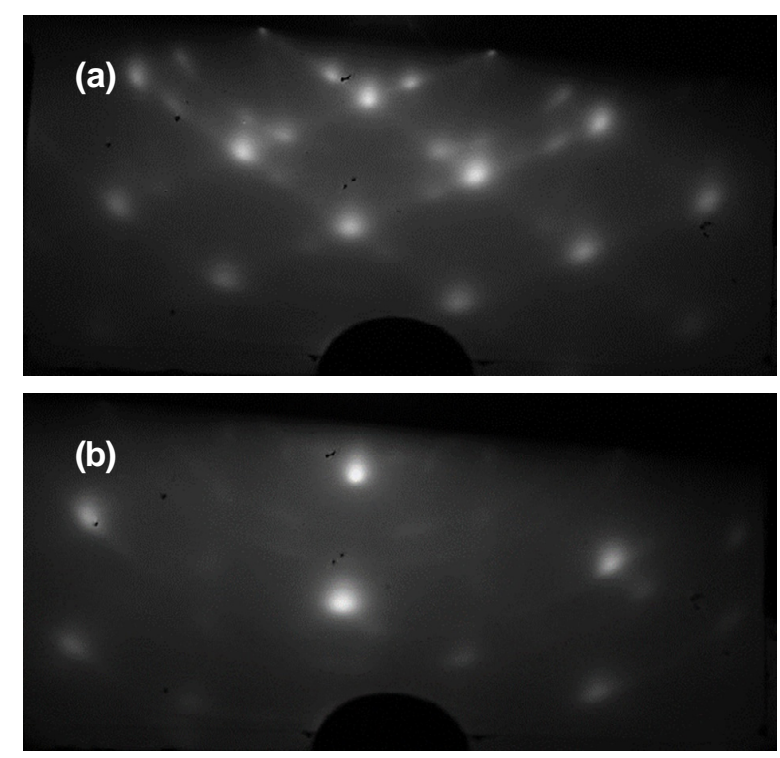

Fig. 6. RHEED patterns of $\mathrm{SiC}$ samples grown on $\mathrm{Si}(100) / r$-plane $\mathrm{Al}_{2} \mathrm{O}_{3}$; projected onto the axis [001] (a) and projected onto the axis [011] (b).The patterns are similar for both Fab-2-R-plane and Fab-1R-plane sapphire.
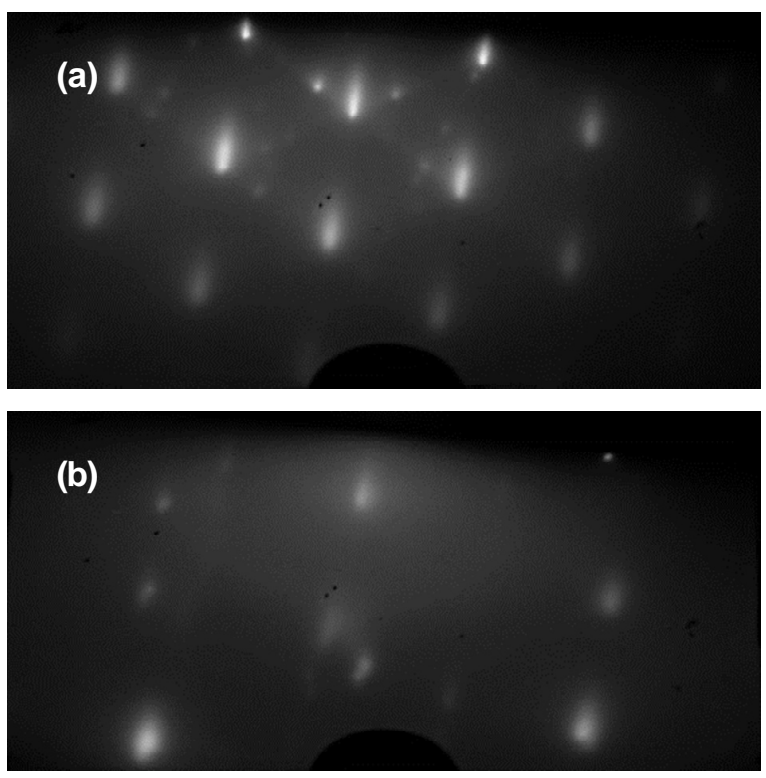

Fig. 7. RHEED patterns of the SiC layer grown on single-crystal $\mathrm{Si}(100)$ surface; projected onto the axis [001] (a) and projected onto the axis [011] (b).

RHEED patterns of SiC grown on Fab-1-R-plane sapphire, since RHEED patterns of the SiC layer grown on Fab-2-R-plane sapphire are quite similar. However, they are slightly worse than the patterns of the $\mathrm{SiC}$ on Fab-1-R-plane. The reflexes of this film are more «blurred», which indicates a more textured structure grown on the Fab-2-R-plane sapphire substrate, which coincides with the analysis above.

It should be noted that RHEED patterns shown in figure 6 almost correspond to RHEED patterns of 
the SiC layer grown on a single-crystal Si (100) by the method of atomic substitution in the same synthesis conditions as the samples $\mathrm{SiC} / \mathrm{Si}(100) / \mathrm{r}$ plane $\mathrm{Al}_{2} \mathrm{O}_{3}$ (Fig. 7).

A comparison of the data in Figs. 6 and 7 allows one to conclude that the structure of the surface of SiC layers on the sapphire and on the single-crystal Si almost coincide. The reflexes in Fig. 6 are more blurred, the twinning phase is more clearly visible, the distances between the reflexes are more distorted, which may indicate mechanical deformations of the SiC film on the sapphire.

Fig. 8 shows RHEED patterns of the surface of the $\mathrm{SiC}$ sample grown on $\mathrm{Si}(111) / \mathrm{c}$-plane $\mathrm{Al}_{2} \mathrm{O}_{3} \mathrm{Fab}$ 2-C-plane.

It can be concluded from the RHEED patterns in Fig.8, that along with the polycrystalline phase, which is characterized by continuous circles on the pattern, there are clear epitaxial reflexes, and even "some kind" of Kikuchi lines appear. Note, that on the initial $\mathrm{Si}(111) / c$-plane $\mathrm{Al}_{2} \mathrm{O}_{3}$ surface, as can be seen from the data shown in Fig. 1c, nothing of the kind was observed. This means that during the process of conversion of the textured $\mathrm{Si}(111) / \mathrm{c}$-plane $\mathrm{Al}_{2} \mathrm{O}_{3}$ layer into the $\mathrm{SiC}(111) / \mathrm{c}$-plane $\mathrm{Al}_{2} \mathrm{O}_{3}$ layer, a transformation occurred, which led to a certain epitaxial ordering of the surface of SiC. The detected effect is directly related to the process described by reaction (3) equation. At this stage, the material shrinks and, strictly speaking, at this moment SiC nuclei appear $[3,4]$. This process is similar to the
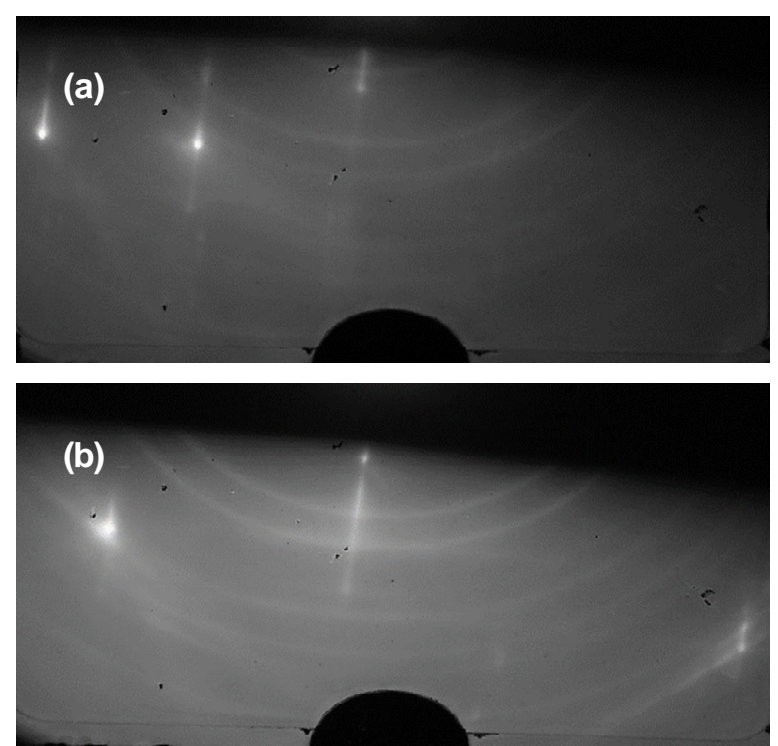

Fig. 8. RHEED patterns of the $\mathrm{SiC}$ layer, grown on $\mathrm{Si}(111) / c-p l a n e \mathrm{Al}_{2} \mathrm{O}_{3}$ (Fab-2-C-plane sapphire), projected onto the axis [110] (a) and projected onto the axis [112] (b).
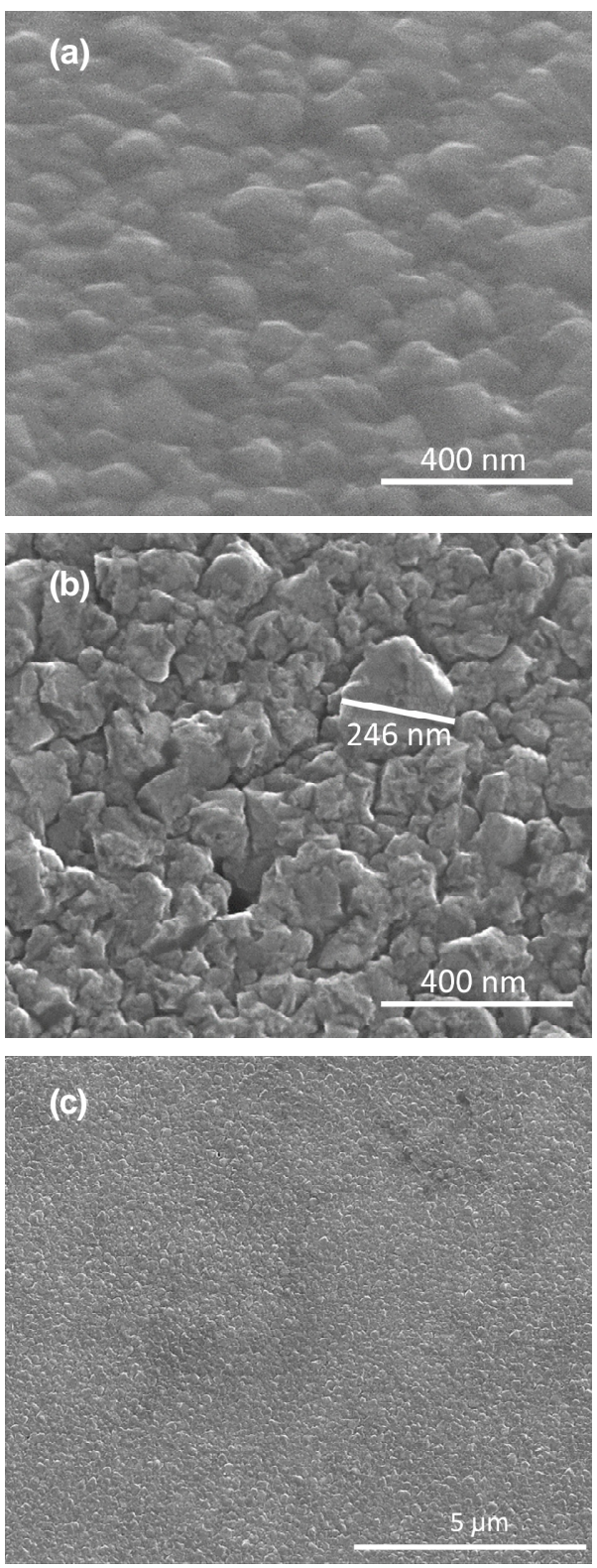

Fig. 9. SEM images of the surface of the initial $\mathrm{Si}(111) / c-p l a n e \mathrm{Al}_{2} \mathrm{O}_{3}$ sample (a) and the same sample after conversion into $\mathrm{SiC}$ by reaction (1) (b, c); (c) is the same area as in fig. (b) but on a smaller scale.

formation of crystals within a solid, or to the socalled formation of crystalline geodes, i.e. crystal growth within a solid with formation of voids. SEM images of the process of $\mathrm{Si}(111) / \mathrm{c}$-plane $\mathrm{Al}_{2} \mathrm{O}_{3}$ transformation into $\mathrm{SiC}(111) / \mathrm{c}$-plane $\mathrm{Al}_{2} \mathrm{O}_{3}$ are shown in Fig. 9.

It is clearly seen in Fig. 9 that during the process of Si-to-SiC conversion large $\mathrm{SiC}$ crystals of about $250 \mathrm{~nm}$ are being formed on the surface. Fig. $9 \mathrm{c}$ shows that the surface is covered with small crystalline "flakes", on average oriented in one direction. 

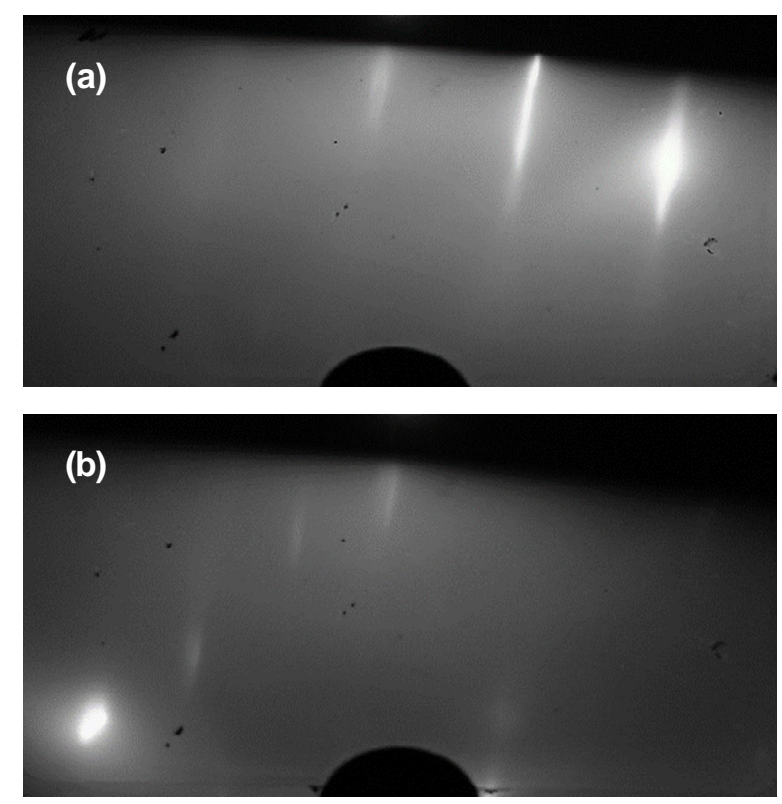

Fig. 10. RHEED patterns of the SiC layer, grown on the single-crystal $\mathrm{Si}(111)$; projected onto the axis [110] (a) and projected onto the axis [112] (b).

Fig. 10 shows RHEED patterns of the $\mathrm{SiC}$ layer grown on single-crystal $\mathrm{Si}(111)$ by the method of atomic substitution in the same synthesis conditions as the sample $\mathrm{SiC} / \mathrm{Si}(111) / c-p l a n e \mathrm{Al}_{2} \mathrm{O}_{3}$.

Comparison of Figs. 9 and 10 gives one the possibility to see that the SiC layer grown on monocrystalline $\mathrm{Si}$ is much better oriented than the layer grown on sapphire. However, as follows from our study of the growth of $\mathrm{SiC}$ on $\mathrm{Si}(100) / r$-plane $\mathrm{Al}_{2} \mathrm{O}_{3}$ substrates, it is sufficient to deposit a highquality epitaxial $\mathrm{Si}$ layer on sapphire, and the resulting SiC layer will be also epitaxial. Moreover, the higher the degree of monocrystallinity of the initial Si layer, the higher will be the degree of monocrystallinity of the resulting $\mathrm{SiC}$ layer.

Fig. 11 shows the dependencies of the dielectric constant (ellipsometric spectra), i.e. the dependency of its real part $\varepsilon_{1}$ and its imaginary part $\varepsilon_{2}$ on the photon energy measured on $\mathrm{SiC}$ samples grown on $\mathrm{Si}(100) /$ - -plane $\mathrm{Al}_{2} \mathrm{O}_{3}$ and $\mathrm{Si}(111) / \mathrm{c}$-plane $\mathrm{Al}_{2} \mathrm{O}_{3}$ using J.A. Woollam ellipsometer. The dotted lines in Fig. 11 show the theoretical dependencies of $\varepsilon$ on the photon energy obtained in the framework of the model proposed in [11]. In general, the dependencies of the dielectric constant of $\mathrm{SiC}$ samples grown on sapphire Fab-1-R-plane and Fab-2-R-plane differ a little from each other, that is why Fig. 11 shows the dielectric constant spectrum of the only one sample grown on sapphire Fab-1-R-plane.

According to calculations made using the dielectric constant spectral data, the concentration of
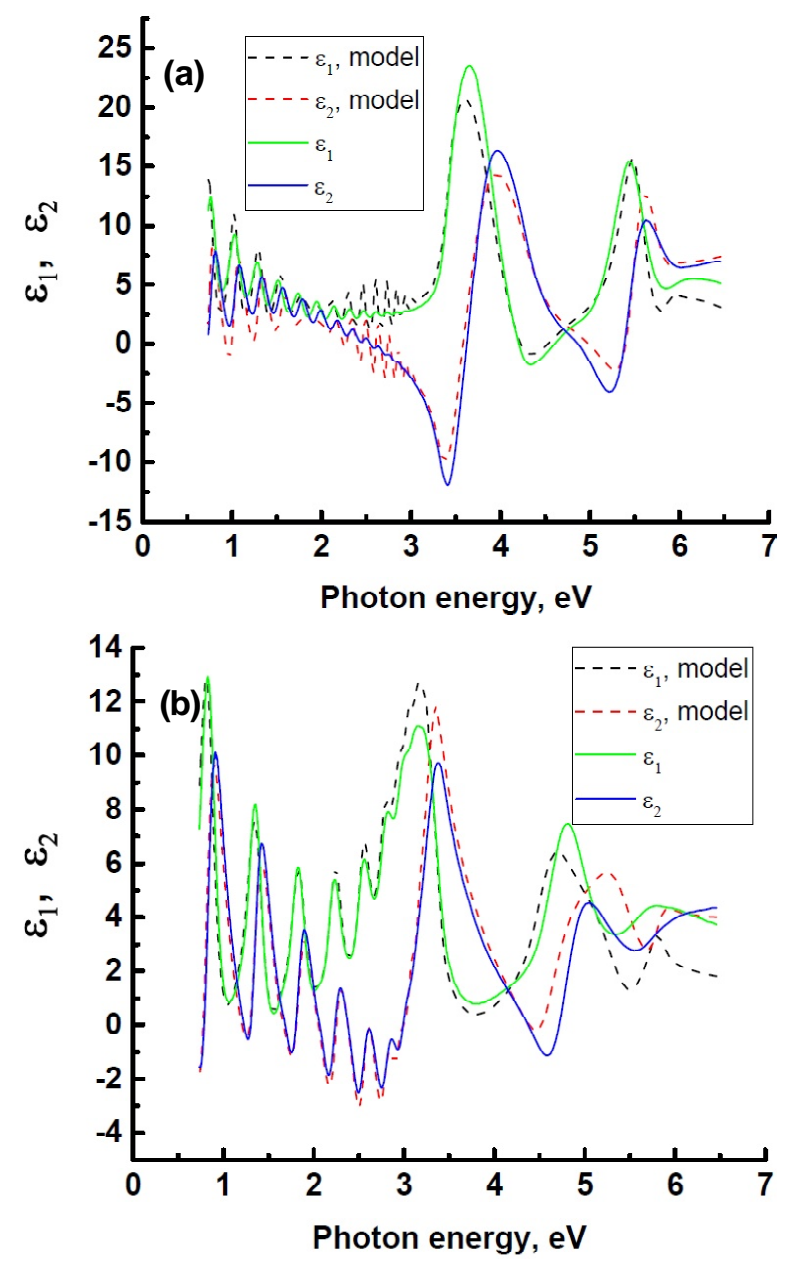

Fig. 11. Dependencies of the dielectric constants of $\mathrm{SiC}$ samples on the photon energy. $\varepsilon_{1}$ is the real part of the dielectric constant, $\varepsilon_{2}$ is its imaginary part. The dotted line presents the theoretical dependency of $\varepsilon$ on the photon energy obtained in the framework of the model proposed in [11]; (a) $\mathrm{SiC} / \mathrm{Si}$ (100) on Fab-1-R-plane sapphire; (b) $\mathrm{SiC} / \mathrm{Si}$ (111) on Fab-2-C-plane sapphire.

carbon - vacancy structures in the sample $\mathrm{SiC} /$ $\mathrm{Si}(100) /$ Fab-2-R-plane sapphire is about 6\%. The volume fraction of pores in $\mathrm{Si}$ is about $30 \%$. In the sample $\mathrm{SiC} / \mathrm{Si}(100)$ on Fab-1-R-plane sapphire, these values are slightly lower. The concentration of carbon-vacancy structures in this sample is about $5 \%$, and the volume fraction of pores in $\mathrm{Si}$ is about $24 \%$. In the sample $\mathrm{SiC} / \mathrm{Si}$ (111) grown on Fab-2-Cplane sapphire, the concentration of carbon-vacancy structures is higher and equals to $9 \%$. At the same time, the volume fraction of pores in $\mathrm{Si}$ in this sample is much lower and equals to $20 \%$. This is not surprising, since the Si(111) film grown on the sapphire was almost two times thinner than $\mathrm{Si}(100)$ films, and in addition it was more "loose" and tex- 


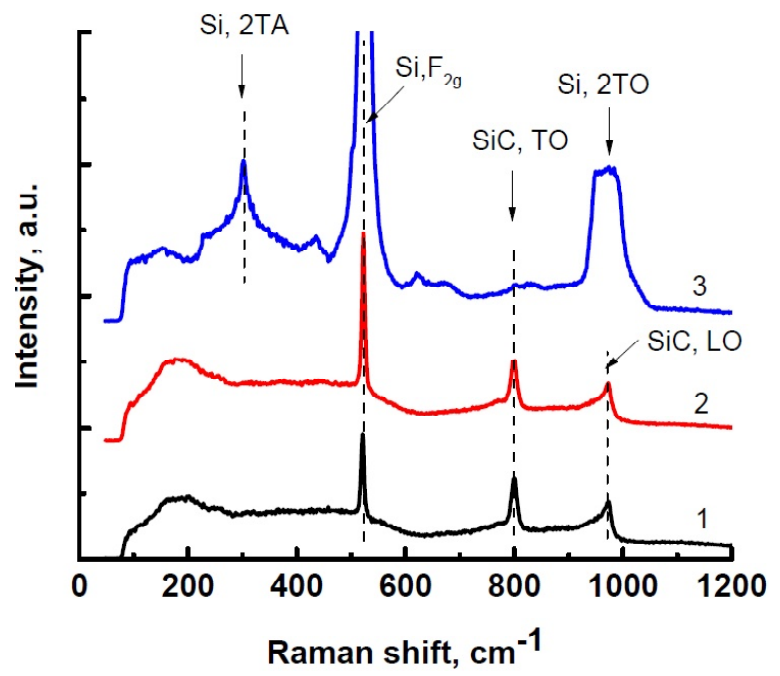

Fig. 12. Raman spectra of $\mathrm{SiC}$ samples grown on $\mathrm{Si}(100) / \mathrm{r}$-plane $\mathrm{Al}_{2} \mathrm{O}_{3}$ and $\mathrm{Si}(111) / \mathrm{c}$-plane $\mathrm{Al}_{2} \mathrm{O}_{3} ;$; 1 ) $\mathrm{SiC} / \mathrm{Si}(100)$ on sapphire Fab-2-R-plane; (2) $\mathrm{SiC} / \mathrm{Si}$ (100) on sapphire Fab-1-R-plane; (3) SiC/Si (111) on sapphire Fab-2-C-plane.

tured. The reaction of convertation of $\mathrm{Si}$ into $\mathrm{SiC}$ affected almost all of silicon, which is clearly seen on SEM micrographs (Figs. 4c and 4d). In places where the original $\mathrm{Si}$ was more defective, it almost completely turned into SiC (Fig. 4c). In places where $\mathrm{Si}$ was less defective, it practically does not contain pores. Some kind of regularity is also observed in $\mathrm{SiC}$ samples grown from $\mathrm{Si}(100)$. The more defective the initial silicon layer, the more carbon-vacancy structures in SiC are contained, and in nontransformed $\mathrm{Si}$ (under a layer of $\mathrm{SiC}$ ) there are more pores.

In conclusion, for completeness, we present data on the study of samples by the method of Raman spectroscopy. This data is shown in Fig. 12. Note that the Raman spectra of SiC-on-Si films synthesized by the method of atomic substitution were studied in detail for the first time in a series of papers $[8,41]$. In these papers, firstly, all the main Raman peaks were analyzed in detail and compared with the corresponding modes of the phonon oscillations of various $\mathrm{SiC}$ polytypes. Secondly, it was found that SiC Raman lines over pores are much more intense than over the smooth surface of the substrate. It was suggested that the reason for the difference in line intensity lies in the additional amplification of the Raman spectra due to the additional reflection of the laser beam inside the cavities covered with SiC. The Raman spectra of SiC samples on the sapphire (Fig. 12) generally coincide with the Raman spectra studied in $[41,42]$. Differences exist only in the details caused by differ- ent conditions of film synthesis in the present work and in works [8,41].

As follows from Fig. 12 on $\mathrm{SiC} / \mathrm{Si}(100) / r$-plane $\mathrm{Al}_{2} \mathrm{O}_{3}$ samples (Fig. 12, spectra 1 and 2), SiC Raman lines are very intensive, which indicates high quality of the $\mathrm{SiC}$ layer. The spectra contain both high-intensity SiC TO $\left(796 \mathrm{~cm}^{-1}\right)$ and LO $\left(968 \mathrm{~cm}^{-1}\right)$ lines, which indicate the presence of the $3 \mathrm{C}$-SiC phase [8.41.42]. The silicon line $F_{2 g}\left(520 \mathrm{~cm}^{-1}\right)$ [43] is significantly less intense than on the initial samples before the growth of $\mathrm{SiC}$, but is nonetheless present in the spectra, which allows us to conclude that $\mathrm{Si}$ is not fully converted into $\mathrm{SiC}$. This is also can be clearly seen in SEM images presented in Fig. 4. The main Raman line of silicon carbide TO (796 $\mathrm{cm}^{-1}$ ) (Fig. 12, spectrum 3) on the $\mathrm{SiC} / \mathrm{Si}(111) /$ c-plane $\mathrm{Al}_{2} \mathrm{O}_{3}$ sample has extremely low intensity. The Raman lines of silicon $\mathrm{F}_{2 \mathrm{~g}}\left(520 \mathrm{~cm}^{-1}\right), 2 \mathrm{TA}$, and 2TO dominate in this spectrum. It could be assumed that the thickness of the SiC film on this sample is small, but, taking into account the studies presented above, it is possible to associate such a small intensity with the imperfection of the $\mathrm{SiC}$ layer on the substrate. Note that Raman spectroscopy, unlike the work [41] and the XRD-studies (Fig. 5), failed to determine hexagonal polytypes in the samples because corresponding Raman lines in these spectra (if they exist) have too low intensity.

\section{CONCLUSION}

A new method for growth of SiC films on a sapphire was proposed, experimentally proved and described in detail. The method consists of a series of successive stages. In the first stage, a Si layer should be preliminarily deposited on a sapphire substrate. If it is required to obtain the epitaxial $\mathrm{SiC}$ layer, then the previously deposited $\mathrm{Si}$ layer should also be epitaxial. It can be done, for example, using CVD method [32-34]. In the second stage, the surface of the Si film should be cleaned of a silicon oxide and passivated with a hydrogen layer, for example, according to the method described $[35,36]$. At the last stage, the Si layer should be transformed into $\mathrm{SiC}$ using the method of atomic substitution, developed in [1-4].

\section{ACKNOWLEDGEMENTS}

The Russian Science Foundation (project no. 1412-01102) supported this study. The study was performed using the equipment of the Unique scientific facility (USF) "Physics, chemistry, and mechanics of crystals and thin films" of the Institute of Prob- 
lems of Mechanical Engineering, Russian Academy of Sciences (St. Petersburg). The authors are grateful to the staff of the Research Laboratory of RMTA MIET Gerasimenko N.N. and Smirnov D.I. for the Xray analysis of $\mathrm{Si}$ and $\mathrm{SiC}$ thin films and for help in interpreting the results.

\section{REFERENCES}

[1] S.A. Kukushkin and A.V. Osipov // Phys. Solid State. 50 (2008) 1238.

[2] S.A. Kukushkin and A.V. Osipov //J. Appl. Phys. 113 (2013) 024909.

[3] S.A. Kukushkin and A.V. Osipov // J. Phys. D: Appl. Phys. 47 (2014) 313001.

[4] S. A. Kukushkin, A. V. Osipov and N. A. Feoktistov // Phys. Solid State. 56 (2014) 1507.

[5] S. A. Kukushkin and A. V. Osipov // Phys. Solid State. 59 (2017)1238.

[6] S.A. Kukushkin and A.V. Osipov // J. Phys. D: Appl. Phys. 50 (2017) 464006.

[7] S. A. Kukushkin, A. V. Osipov and R.S. Telyatnik // Phys. Solid State. 58 (2016) 971.

[8] T.S. Perova, J.Wasyluk, S.A. Kukushkin, A.V. Osipov, N.A. Feoktistov and S.A. Grudinkin // Nanoscale Res. Lett. 5(9) (2010)1507.

[9] L. M. Sorokin, N. V. Veselov, M. P. Shcheglov, A. E. Kalmykov, A. A. Sitnikova, N. A. Feoktistov, A. V. Osipov and S. A. Kukushkin// Technical Physics Letters. 34 (2008) 992.

[10] S.A. Kukushkin, K.Kh. Nussupov, A. V. Osipov, N. B. Beisenkhanov and D. I. Bakranova // Superlattices and Microstructures. 111 (2017) 899.

[11] S.A. Kukushkin and A.V. Osipov //Technical Physics Letters. 42 (2016) 175.

[12] Yu. E. Kitaev, S. A. Kukushkin, A. V. Osipov and A. V. Redkov // Phys. Solid State. 60 (2018) 2066.

[13] S.A. Kukushkin and A.V. Osipov // Technical Physics Letters. 43 (2017) 631.

[14] S.A. Kukushkin and A.V. Osipov //J. Phys. Solid State. 60 (2018) 1891.

[15] S.A. Kukushkin, A.V. Osipov and I.P. Soshnikov // Rev.Adv.Mater. Sci. 52 (2017) 29.

[16] S. A. Kukushkin and A. V. Osipov // Semiconductors 47 (2013) 1551.

[17] S. A. Grudinkin, S. A. Kukushkin, A. V. Osipov and N. A. Feoktistov // Phys. Solid State. 59 (2017) 2430.

[18] Yu. E. Kitaev, S. A. Kukushkin and A. V. Osipov // Phys. Solid State. 59 (2017) 30.
[19] Xiao Tang, Kobchat Wongchotigul and Michael G. Spencer // Appl. Phys. Lett. 58 (1991) 917.

[20] B. S. Sywe, Z. J. Yu, S. Burckhard, J.H. Edgar and J. Chaudhuri // J. Electrochem. Soc. 141 (1994) 510.

[21] T. J. McArdle, J. O. Chu, Yu Zhu, Z. Liu, M. Krishnan, C. M. Breslin, C. Dimitrakopoulos, R. Wisnieff and A. Grill // Appl. Phys. Lett. 98 (2011) 132108.

[22] L. Cheng, A. J. Steckl and J. Scofield // IEEE Transactions on Electron Devices 50 (2003) 2159.

[23] Jian Chao Li, Paolo Batoni and Raphael Tsu // Thin Solid Films 518 (2010) 1658.

[24] Tien-Tung Luong, Binh Tinh Tran, Yen-Teng Ho, Ting-Wei Wei, Yue-Han Wu, Tzu-Chun Yen, Lin-Lung Wei, Jer-Shen Maa and Edward Yi Chang // Electron. Mater. Lett. 11 (2015) 352.

[25] R. Beisenov, R. Ebrahim , Z.A. Mansurov, S.Zh. Tokmoldin, B.Z. Mansurov and A. Ignatiev // Eurasian ChemicoTechnological Journal. 15 (2013) 25.

[26] Jack O. Chu, Christos D. Dimitrakopoulos, Alfred Grill, Timothy J. McArdle, Katherine L. Saenger,L. Robert and Yu Zhu, US Patent No.: US 2012/0112198 A1, Pub. Date: May 10, 2012.

[27] K. Shibata, Sh. Haranda and T. Ujihara // Materials Science Forum 821-823 (2015) 185.

[28] Cristoloveanu S. and Li Sh, Electrical characterization of silicon-on-insulator materials and devices (Springer Science and Business Media, New York, 1995).

[29] D. Munteanu, S. Cristoloveanu, O. Rozeau, J. Jomaah, J. Boussey, M. Wetzel, P. de la Houssaye and L. Lagnado // J. Electrochem. Soc. 148 (2001) 218.

[30] J.P. Colinge // NATO Science Series. High Technology. 73 (1999) 249.

[31] G.K. Celler, S, Cristoloveanu // J. Appl. Phys. 93 (2003) 4955.

[32] E. M. Sokolov, S. D. Fedotov, V. N. Statsenko, S. P. Timoshenkov and A. V. Emelyanov // Semiconductors 51 (2017) 1692.

[33] S. D. Fedotov, S. P. Timoshenkov, D. I. Smirnov, E. M. Sokolov and V. N. Statsenko, In: Proceedings of the 2017 IEEE Russia Section Young Researchers in Electrical and Electronic Engineering Conference (2017 
ElConRus), Part II, Feb. 1-3 (St. PetersburgMoscow, 2017), p. 264.

[34] S. D. Fedotov, D. I. Smirnov, E. M. Sokolov and V. N. Statsenko, In: Proceedings of the 2018 IEEE Russia Section Young Researchers in Electrical and Electronic Engineering Conference (2018 EIConRus), Part II, (Moscow, 2018), p. 1613.

[35] I. P. Kalinkin, S. A. Kukushkin and A. V.Osipov, RF Patent Appl. No 200612032 (2006).

[36] I. P. Kalinkin, S. A. Kukushkin and A. V. Osipov // Semiconductors 52 (2018) 802.

[37] Yu. I. Folomeikin, I.M. Demonis, E.N. Kablov, S.I. Lopatin and V.L. Stolyarova // Doklady Chemistry. 399 (2004) 257.
[38] S.A. Kukushkin and A.V. Osipov // Phys. Solid State. 58 (2016) 747.

[39] J. Aguilar, J. Rodríguez and M. Hinojosa // Journal of Microwave Power \& Electromagnetic Energ 36 (2001) 169.

[40] V.N. Bessolov, E.V. Konenkova, S.A. Kukushkin, A.V. Osipov and S.N. Rodin // Rev.Adv.Mater. Sci. 38 (2014) 75.

[41] T. S. Perova, J. Wasyluk, S. A. Kukushkin, A. V. Osipov, N. A. Feoktistov and S. A. Grudinkin // Nanoscale Res Lett. 5 (2010) 1507.

[42] S.I. Nakashima and H. Harima // Physica Status Solidi (a). 162 (1997) 39.

[43] H. Richter, Z.P. Wang and L. Ley // Solid State Communications 39 (1981) 625. 